\title{
Integrated geophysical surveys for the knowledge of a monument of Lecce: the sixteenth-century fortifications
}

\author{
Giacomo Di Giacomo ${ }^{1}$, Lara De Giorgi ${ }^{1}$, Immacolata Ditaranto ${ }^{1}$, Giovanni Leucci ${ }^{1}$, Ilaria Miccoli ${ }^{1}$, \\ G. Scardozzi ${ }^{1}$
}

${ }^{1}$ Institute for Archaeological and Monumental Heritage - National Research Council (IBAM-CNR) c/o Campus Universitario, Lecce, Italy

\begin{abstract}
Within the project for the restoration of the northern section of the sixteenth-century city wall of Lecce, CNR-IBAM carried out geophysical surveys aimed at the study and the reconstruction of the fortifications system. In particular, the investigations focused on a wide band of land outside the two bastions at the northern far end of the fortifications. The integrated use of GPR and ERT systems has allowed to detect anomalies related to the main ditch outside the city wall and to characterize the rocky bench in which it was excavated; at the time of the surveys, this ditch was still buried, and the results of the measurements have guided its excavations. Moreover, the investigations have allowed to identify also other possible ditches or quarries and more ancient structures, which subsequent archaeological excavations have dated at the Roman period. Moreover, geophysical surveys highlighted the presence of modern walls, corresponding with the foundations of the stadium constructed in the first half of the 1900 s close to the fortifications. So, geophysical investigations were very important since they allowed not only to direct the archaeological excavations, but also because they allowed to formulate some hypotheses on the ancient topography of the not excavated area.
\end{abstract}

\section{Section: RESEARCH PAPER}

Keywords: Archaeology; Geophysics; Measurements; Ancient walls

Citation: Giacomo Di Giacomo, Lara De Giorgi, Immacolata Ditaranto, Giovanni Leucci, Ilaria Miccoli, G. Scardozzi, Integrated geophysical surveys for the knowledge of a monument of Lecce: the sixteenth-century fortifications, Acta IMEKO, vol. 7, no. 3, article 12, October 2018, identifier: IMEKO-ACTA07 (2018)-03-12

Section Editor: Sabrina Grassini, Politecnico di Torino, Italy

Received March 11, 2018; In final form August 16, 2018; Published October 2018

Copyright: (๑) 2018 IMEKO. This is an open-access article distributed under the terms of the Creative Commons Attribution 3.0 License, which permits unrestricted use, distribution, and reproduction in any medium, provided the original author and source are credited

Corresponding author: Giovanni Leucci, giovanni.leucci@cnr.it

\section{INTRODUCTION}

In 2014 and in 2015 integrated geophysical surveys were carried out outside the northern section of the sixteenth-century city walls of Lecce by a team of researchers of the Laboratory of Geophysical applied to the Archaeological and Monumental Heritage and the Laboratory of Ancient Topography, Archaeology and Remote Sensing of CNR-IBAM in Lecce. The investigations were carried out in cooperation with the chair of the Medieval Archaeology of the University of Salento, responsible for archaeological excavations aimed at studying the ancient remains inside and outside the sixteenth-century city walls. The investigations were performed during the massive restoration works promoted by the Municipality of Lecce and aimed at enhancement of value of this section of the city walls, including the reconstruction of the original aspect of the fortifications and the external moat.
The main goal of the geophysical surveys was to identify the large moat outside the city walls, excavated in the rocky bank (quite close to the surface) and filled with soil probably in the 18th century or at the beginning of the 19th century. In particular, the geophysical measurements were based on Ground-penetrating Radar (GPR) and Electrical Resistivity Tomography (ERT) techniques; in this paper, the main results of GPR prospecting are presented. First results were presented at the Third International Conference on Metrology for Archaeology [12].

Geophysical survey allowed the researchers to determine the direction, width and depth of the sixteenth-century moat. Hence, the excavation activities in the area immediately outside the fortifications were performed according to the results of the geophysical prospecting, which highlighted also other anomalies related to more ancient remains identified during the 
archaeological excavations as a Medieval dich and a Roman road. At the same time, geophysical surveys have highlighted numerous anomalies related to the recent history of the investigated area, where in 1920s a stadium was built. Lastly, the investigations were also very important since they allowed not only to direct the archaeological excavations, but also to formulate some hypotheses on the ancient topography of the not excavated area.

\section{STUDY AREA}

The study area is located at the northern end of the city walls of Lecce built in sixteenth-century, partially retracing the previous fortifications of the Messapian and Medieval periods (Figure 1). These works were encouraged by the King Carlo V and executed by architect Gian Giacomo dell'Acaya, starting from 1542. This intervention also included the adaptation of the northern end of the defensive system; in fact, this sector was perhaps initially constituted by a lance-shaped bastion, then replaced by a more effective polyorcetic solution consisting of an advanced defensive-work with double bastions tenaille-shaped (nowadays called bastions of S. Francis) [1]. The imposing defensive system was completed by a deep moat, about which all traces have been lost due to a subsequent filling.

Therefore, the main goal of the geophysical investigations, in line with the project of recovery and valorisation of the city walls, was to identify the main moat of this sector of the defensive system and other possible anomalies that could contribute to increase the knowledge of the ancient topography of the area and its transformations over the centuries. At this regard and in order to correctly interpret the data obtained from geophysical surveys, historical maps and historical aerial photographs have been acquired and studied. The aim was to reconstruct the recent history of the investigated area and to document the presence of modern structures nowadays demolished (at this regard see also the previous researches carried out in Lecce [2,3]). Specifically, while in the "Pianta della città di Lecce" drawn by Michele Astut in 1882 the area immediately outside the city walls appeared as an open space, in an aerial photo of 1947 it was partially occupied by modern edifices. In particular, two buildings were immediately to the north of the double bastions and the structures of the

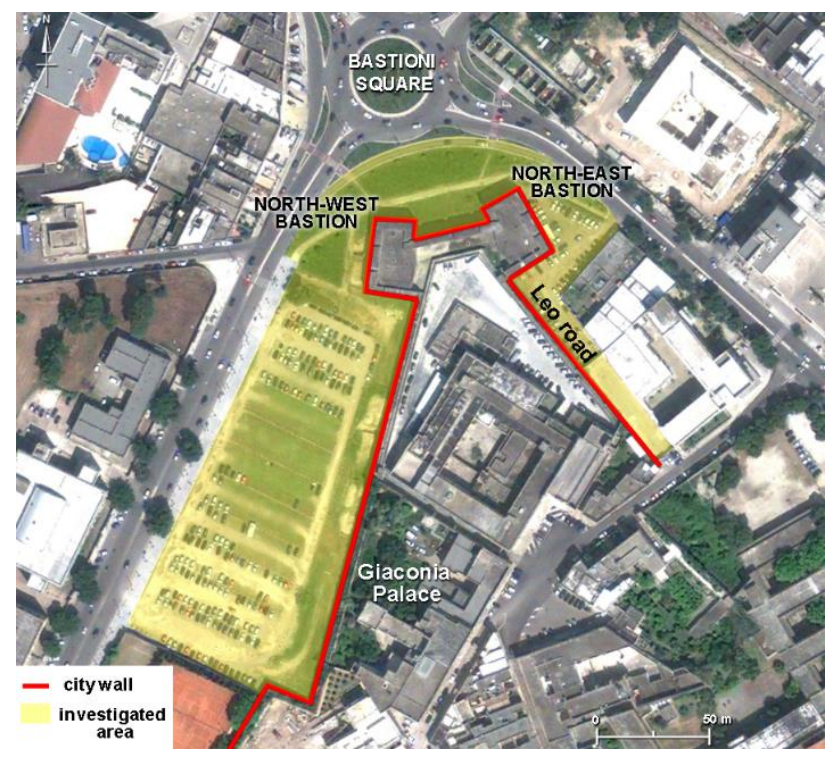

Figure 1. Lecce, the northern side of the sixteenth-century city walls with the Bastion of St. Francis. In yellow the investigated area.

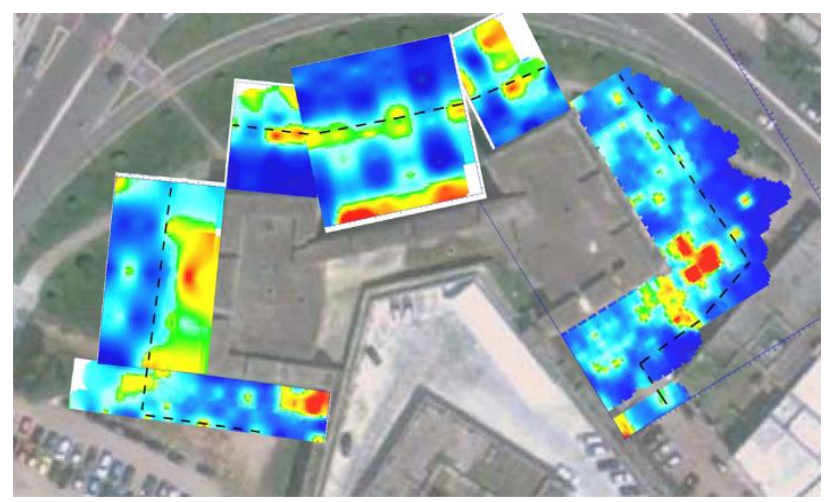

Figure 2. Lecce, area of the St. Francis Bastions: GPR time slices (129-144 cm depth; $200 \mathrm{MHz}$ ) georeferenced on 2010 Google Earth satellite image.

"Campo polisportivo Achille Starace", built in 1924, were in the area immediately to the west of this stretch of city walls. These structures were used until 1966; afterwards, they progressively dropped in disuse and finally were dismantled to use the area, in the last decades, as a parking.

The investigated area involved a stretch of about $500 \mathrm{~m}$ of the city walls and a surface of approximately 1.8 hectares, which was entirely covered by the GPR measurements. Profiles and time slices were positioned using a Differential GPS (DGPS) system and georeferenced on the large-scale archaeological map of Lecce.

\section{GEOPHYSICAL MEASUREMENTS}

Geophysical survey was undertaken in five areas using both Ground-penetrating Radar (GPR) and Electrical Resistivity Tomography (ERT) techniques.

\subsection{GPR data analysis}

For GPR measurements a Ris Hi mod georadar system with dual band $600 \mathrm{MHz}-200 \mathrm{MHz}$ antennae was used.

The GPR data have been gathered with transect with a variable distance $(0.5 \mathrm{~m}$ and $2.0 \mathrm{~m})$ between any two adjacent measurement lines, and the data have been processed by making use of the GPRSLICE code [7]. Particularly, the processing has consisted in zero timing, background removal, gain variable vs.
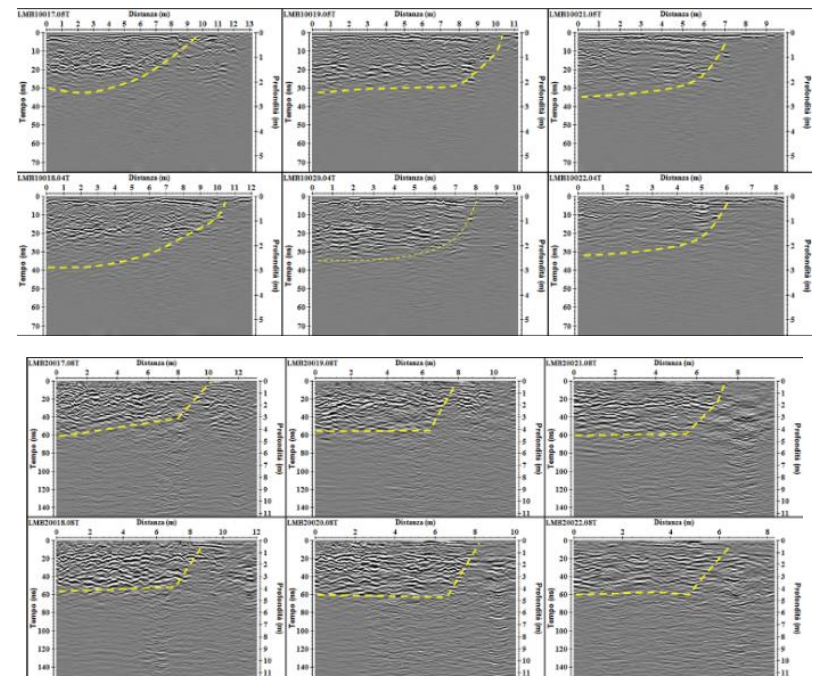

Figure 3. Lecce, area of the St. Francis Bastions: GPR profiles $(600 \mathrm{MHz}$ antenna above, $200 \mathrm{MHz}$ antenna below) acquired in a perpendicular way to the walls. 


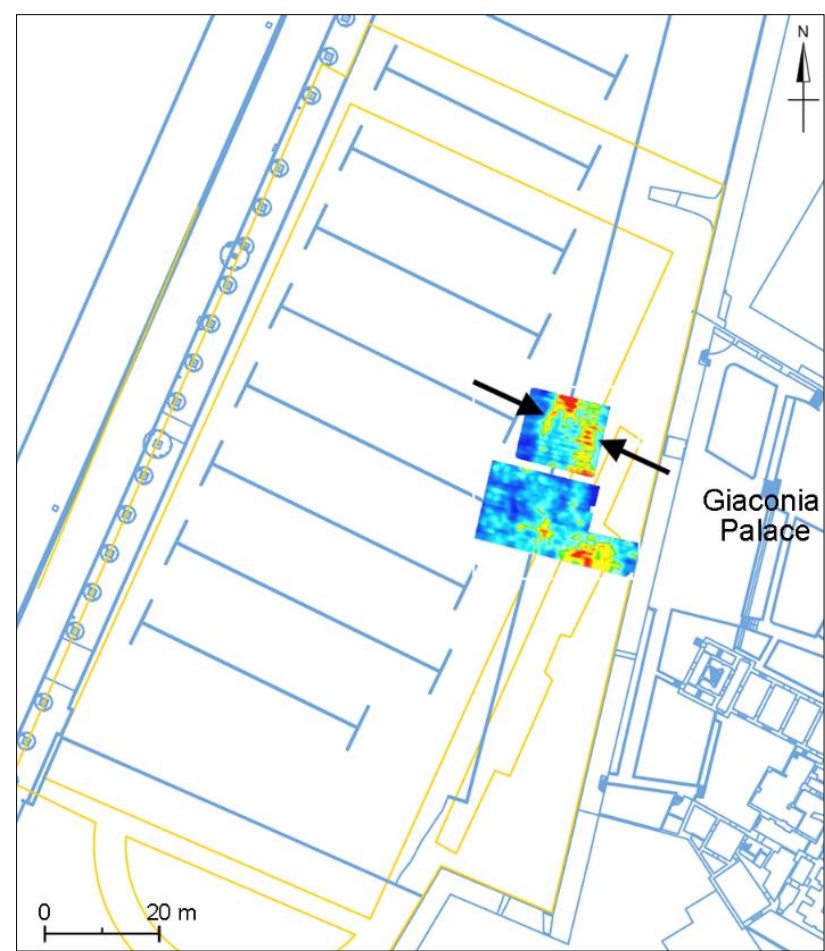

Figure 4. Lecce, sixteenth-century city fortifications: GPR time slices (147-162 $\mathrm{cm}$ depth; $600 \mathrm{MHz}$ antenna) georeferenced in large scale map of Lecce. In yellow the layout of the "Campo Polisportivo Achille Starace".

the depth and Kirchhoff migration [8]. The dielectric constant has been retrieved from the diffraction hyperbolas [8].

The analysis of the GPR data pointed out (Figure 3): the presence of an interface, denominated "base rock", located between $3.0 \mathrm{~m}$ and $4.0 \mathrm{~m}$ in depth; the presence of numerous anomalies that represent a cut in the bed rock; such anomalies are due to the probable presence of the limit of the moat; other reflection events could be related to the probable presence of archaeological structures.

In Figures 2, 4 and 6, the horizontal slices at the respective estimated depths of 129-144 cm (Figure 2), 147-162 cm (Figure 4), and 135-170 cm (Figure 6) are represented. They show the most interesting results among those gathered in the investigated areas.

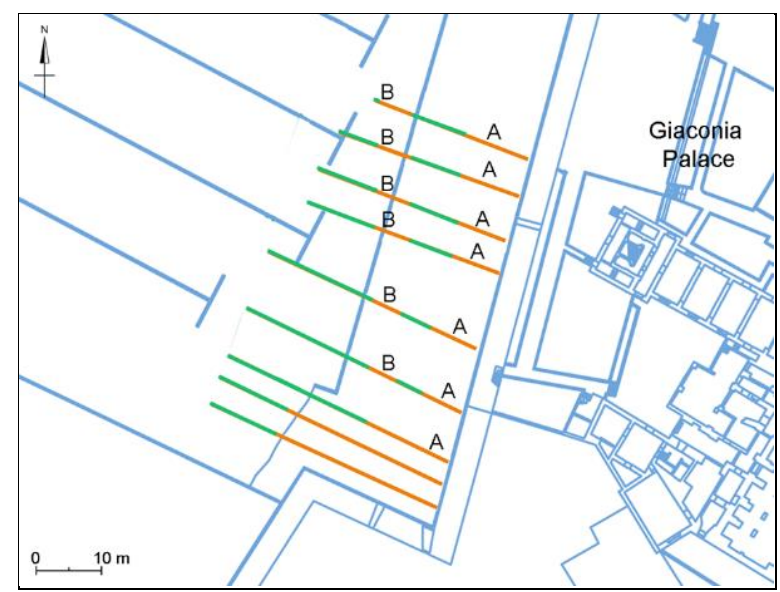

Figure 5. Lecce, sixteenth-century city fortifications. Schematic georeferencing of GPR profiles: A, sixteenth-century moat; B, Medieval moat. In green the bedrock.

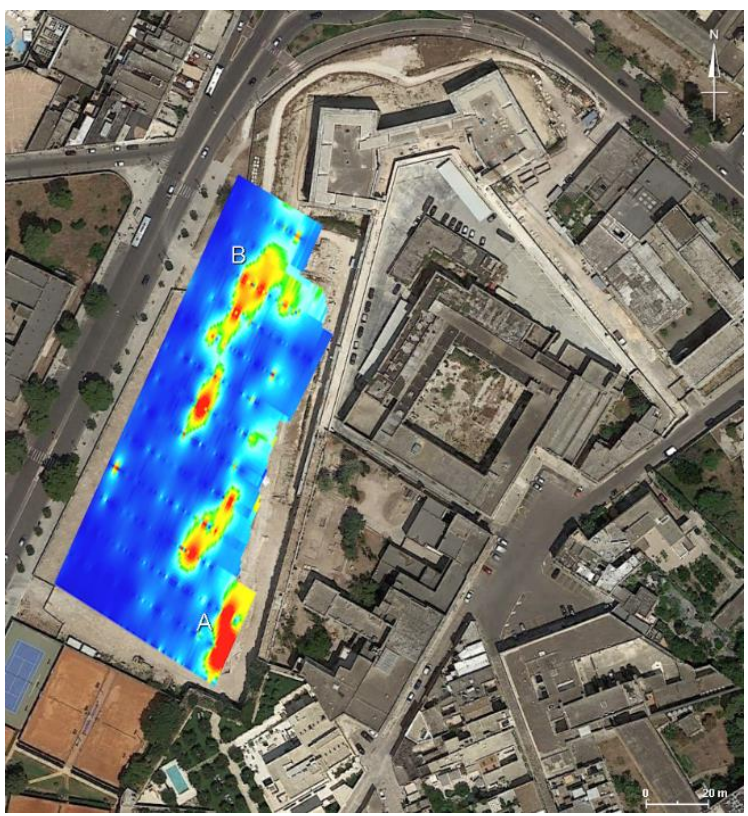

Figure 6. Lecce, sixteenth-century city fortifications. GPR time slices (135$170 \mathrm{~cm}$ depth; $200 \mathrm{MHz}$ antenna) georeferenced on 2015 Google Earth satellite image. A, anomalies related to the stands of old stadium; B, anomalies probably related to the building of changing room of the stadium.
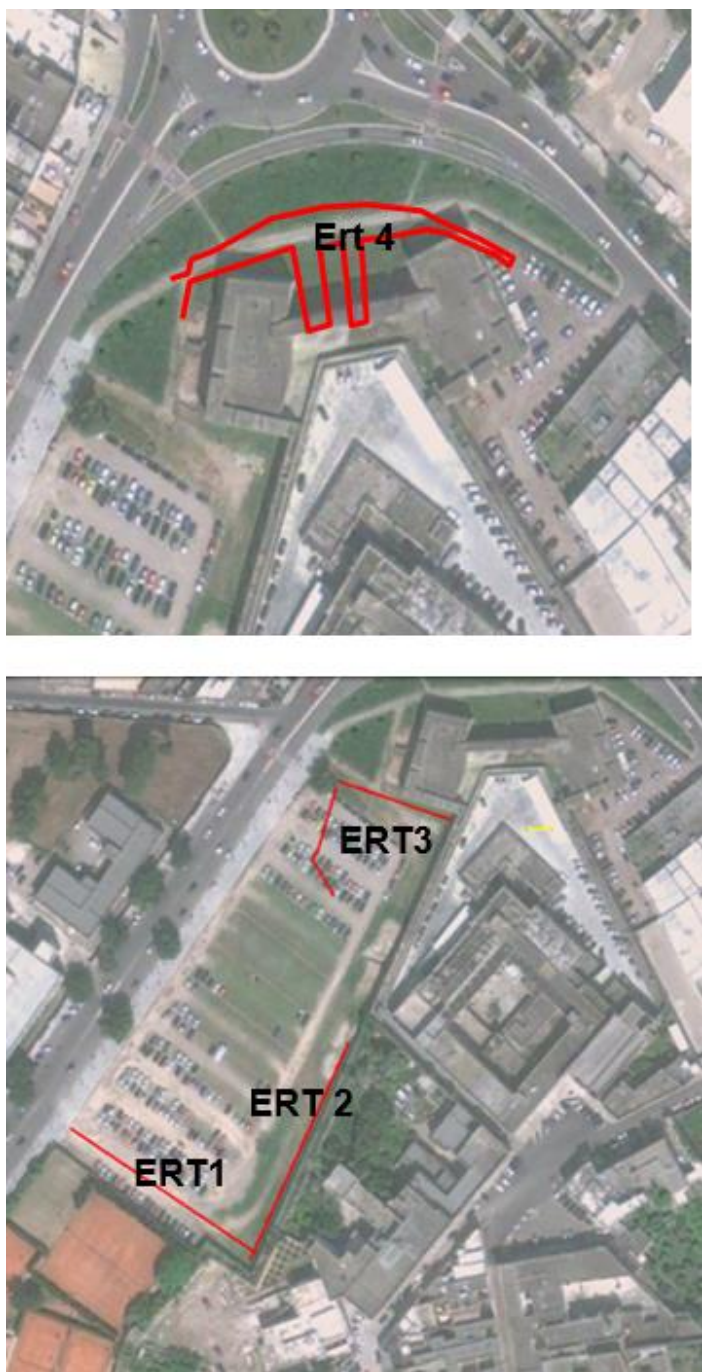

Figure 7. Lecce, ERT measured area. 


\subsection{ERT data analysis}

The surveyed area is approximately $12000 \mathrm{~m}^{2}$ (Figure 7). In order to investigate below the whole area, special ERT arrays were used. The electrodes are distributed in such a way as to surround the area $[9,10,11]$. A dipole-dipole equatorial-parallel array was used. Initially, a $2 \mathrm{D}$ survey is conducted along each perpendicular line or transect. In the next step, the current electrodes remain at the end of one line, while the potential is moved along the line. Then, the current electrodes move one electrode position and the potential electrodes move as previously described. The process is repeated until the current and potential electrodes cover the L geometry. This sequence of observations produces a series of apparent resistivity observations towards and beneath the central portion of the array (Figure 7).

Resistivity data were collected using a Syscal Kid switch device (IRIS Instruments, France) supporting 24 electrodes with two reels of $55 \mathrm{~m}$ long connecting cable and $5 \mathrm{~m}$ maximum separation between electrodes. The electrode separation for all arrays was $2 \mathrm{~m}$. Four profiles, denoted ERT1, ERT2, ERT3 and ERT4, were acquired (Figure 7). A penetration depth of about 6 $\mathrm{m}$ was obtained. After the data acquisition process was performed, the apparent resistivity data were analyzed to identify abnormal measurements with a high standard deviation. This is related to the instrument that allow to perform a number of measurements (in this case 6) and to calculate the mean value with the associated standard deviation (Figure 8). The investigated volume was computed using the software ErtLab (http://www.geostudiastier.it), which uses a Finite Elements algorithm. The true resistivity model computed has an investigation depth of $6 \mathrm{~m}$, which guarantees that the inverted true resistivity model is deeper than the expected features. In order to understand the foundation depth, the analysis of $2 \mathrm{D}$ ERT data was performed.

The 2D ERT data analysis evidenced the presence of a heterogeneous subsurface with resistivity values ranging from 20 to $6000 \Omega \cdot \mathrm{m}$. Moreover, it is possible to note the presence of (Figure 9):

- areas denoted with "A", with resistivity values between 100 and $800 \Omega \cdot \mathrm{m}$; these values indicate the probable presence of the foundation walls;

- areas denoted with "line foundation", with higher resistivity values $(5000-6000 \Omega \cdot \mathrm{m})$ that could be related to the bedrock; - areas denoted with "B", with lower resistivity values (20-30 $\Omega \cdot \mathrm{m}$ ) that could be related to degraded material used to fill the moat.

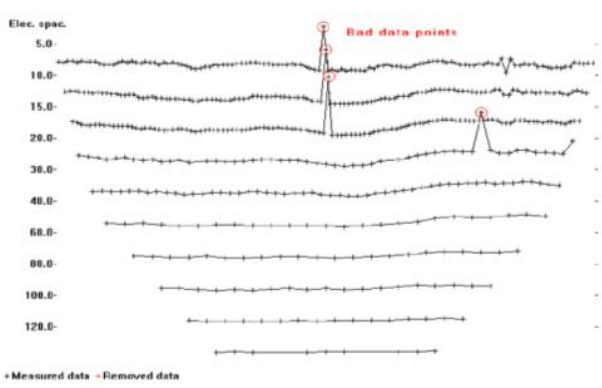

Figure 8. Example of bad data.

For 3D ERT data analysis several horizontal depth slices were produced in order to observe the extension at depth of the resistivity features. Figure 9 shows the slices from 1.0 to $2.5 \mathrm{~m}$ in depth. First, it is possible to note the presence of a heterogeneous subsurface with resistivity values ranging from 1000 to $6000 \Omega \mathrm{m}$. Moreover, it is possible to note the presence of an area delimited by dashed dark lines with resistivity values between 1000 and $4000 \Omega \mathrm{m}$; these values indicate the probable presence of areas where the moat was located.

Figure 11 shows the slices from 1.0 to $2.5 \mathrm{~m}$ in depth. First, it is possible to note the presence of a heterogeneous subsurface with resistivity values ranging from 1000 to $4000 \Omega \cdot \mathrm{m}$. In addition, it is possible to note the presence of an area delimited by dashed dark lines with resistivity values between 1000 and $3000 \Omega \cdot \mathrm{m}$; these values indicate the probable presence of areas where the moat was located.

Geophysical investigations have allowed us to identify numerous anomalies, some closely linked to the sixteenthcentury defensive system, while others are likely to be linked to more ancient structures. The data relating to the characterization of the bedrock on which the walls were built are also very important, especially for the areas outside the two bastions and south of the north-western one. In particular, these measurements highlighted that the surface of the rocky bank was irregular and partially integrated by the foundations of the walls.

\section{THE SIXTEENTH-CENTURY MOAT}

The geophysical surveys clearly documented the sixteenthcentury moat that was excavated immediately outside the city walls, along the whole investigated stretch. The major anomalies related to the moat surrounding the fortifications have been highlighted thanks to the GPR profiles, which were carried out along the entire perimeter of the city walls and with an orientation orthogonal to the fortifications.

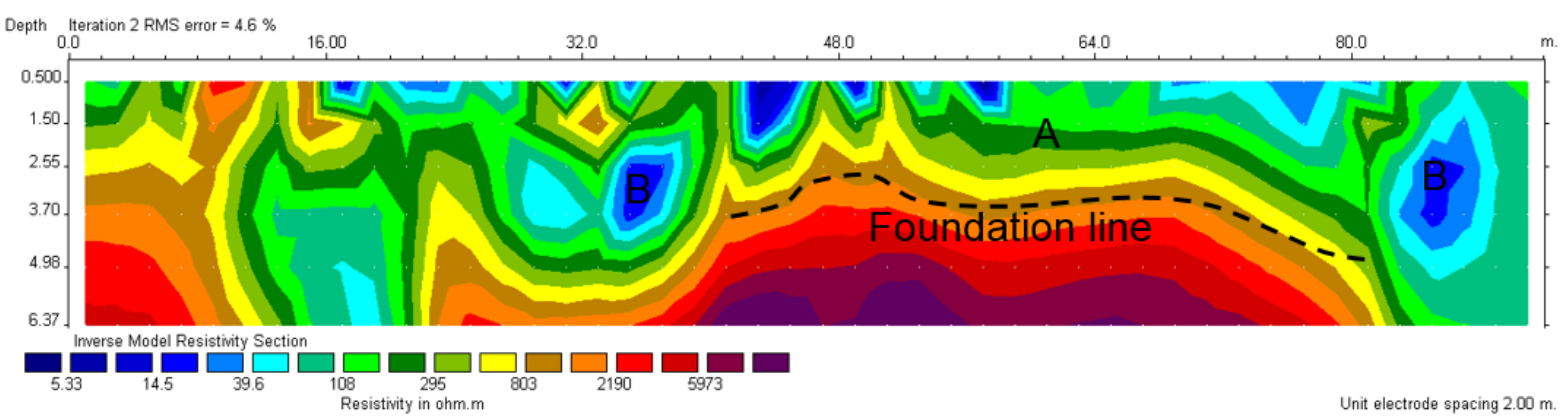

Figure 9. Lecce, 2D ERT related to ERT 2 profile. 
The measurements documented a moat between 6-8 and 10$15 \mathrm{~m}$ large, and between 4.50 and $6 \mathrm{~m}$ deep, excavated in the bedrock and characterized by vertical faces (Figures 3-4); it was filled with soil and blocks. It is interesting to highlight that along L. Leo road, in the stretch south of the north-eastern bastion, the moat has quite the same width of the modern road; so, the modern buildings that flanked the eastern side of the road are built immediately to the east of the edge of the moat.

Moreover, four GPR profiles measured in the area north of the bastions of St. Francis, beyond the moat, have highlighted other anomalies maybe linked to an additional moat (as frequent in the sixteenth-century fortifications systems); this area is under Bastioni Square and was not excavated.

\section{OTHER ARCHAEOLOGICAL REMAINS}

A series of other interesting anomalies was documented by GPR surveys a short distance from the western sector of city walls, in correspondence with Giaconia Palace. These are roughly parallel to the city walls, well visible in particular with the 600 $\mathrm{MHz}$ antenna, at a depth of between 1.25 and $1.60 \mathrm{~m}$ (Figure 4). The anomalies were hypothetically attributed to an ancient structure about 6-7 m wide; subsequent archaeological excavations have clarified that this evidence was a Roman road, of glareata style and contained between two side walls built with large blocks. This road was immediately out of the city of Lupiae (about the urban layout of Lecce in the Roman period see $[4,5,6]$ ) and a stretch of it, about $140 \mathrm{~m}$ long, was brought to light.

In the same area, some GPR profiles (Figure 5) documented anomalies linked to another moat cut in the bedrock, located a few meters to the west of the sixteenth-century moat; subsequent archaeological excavations have clarified that this evidence was a Medieval moat, which was 4-5 m large and partially cut the Roman road. It had a direction NNW-SSE quite divergent by the

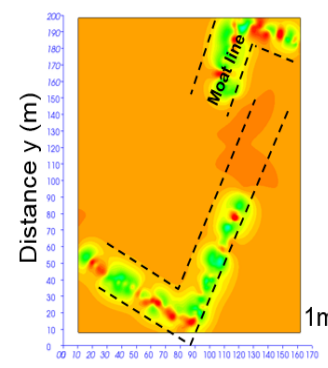

Distance $\mathrm{x}(\mathrm{m})$

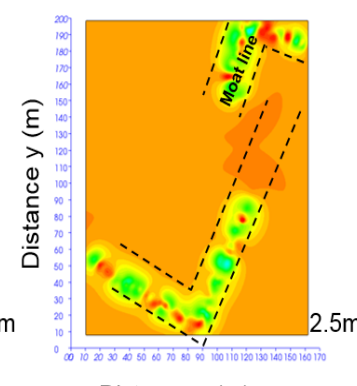

Distance $\times(m)$

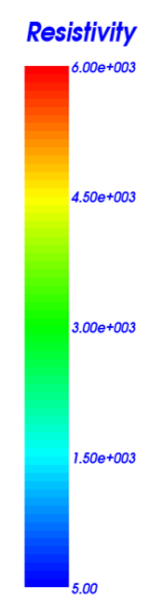

Figure 10. Lecce, 3D ERT related to ERT1, ERT2 and ERT3 profiles.

Roman road and the sixteenth-century city walls, and at its northern end it turned in east direction; two stretches, respectively $85 \mathrm{~m}$ (NNW-SSE orientation) and $25 \mathrm{~m}$ (E-W orientation) were brought to light.

Lastly, again in this area west of the city walls, some GPR profiles have also highlighted other anomalies more to west of the Medieval moat, in a not excavated area; they may be linked to another moat (perhaps pertaining to the sixteenth-century fortification system) or ancient quarrying activities for the extraction of construction stone materials.

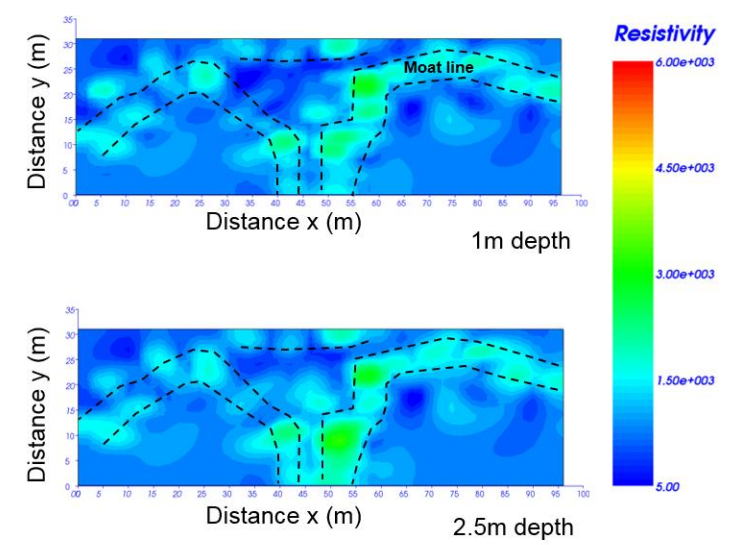

Figure 11. Lecce, 3D ERT related to ERT4 profile.

\section{MODERN STRUCTURES}

Lastly, in the western investigated area, GPR surveys documented also some structures, built in the 1920s using calcareous blocks and pertaining to the "Campo polisportivo Achille Starace"; in particular, a stretch of the eastern stand of the stadium (Figure 6, A) and the building of the dressing room (Figure 6, B) were identified. These structures were abandoned in 1967 and afterwards demolished.

\section{CONCLUSIONS}

The investigations presented in this paper highlight the importance of non-invasive geophysical systems for the research on cultural heritage. Geophysical prospecting, in fact, was able to identify numerous anomalies in the area of the northern city walls of Lecce, which were very useful to direct the archaeological excavations. In particular, the geophysical investigations have identified (i) the sixteenth-century moat outside the city walls, and the presence of (ii) a further moat and (iii) a road, which subsequent archaeological excavations dated respectively to the Medieval and Roman periods. Even some demolished structures of the stadium built in 1920s were identified. The use of GPR method also documented the characteristics of the bedrock, highlighting that its surface is irregular, and many detected geophysical anomalies are related to human activities.

For the interpretation of GPR measurements, the positioning by DGPS system and the georeferencing of profiles and time slices on the large-scale archaeological map of Lecce were very important. Also, the study of the historical maps and documents of the 19th century and first-half of 20 th century was important for the geophysical data interpretation. In fact, only the managing of all the collected and available data allows the understanding of the relations between the documented evidence and the correctly interpretation of the collected the anomalies. About the last matter, obviously the verification through archaeological excavations, which allow precise interpretation and dating, was very important.

\section{REFERENCES}

[1] V. Cazzato, M.Fagiolo, "Lecce. Architettura e storia urbana”, Congedo, Galatina, 2013.

[2] G. Di Giacomo, L. De Giorgi, I. Ditaranto, G. Leucci, I. Miccoli, G. Scardozzi, "Integration of urban archaeology and geophysical prospecting: the research on the public monumental complexes 
of Lupiae (Lecce)", in Proceedings of the $1^{\text {st }}$ IMEKO International Conference, 2015, pp. 521-526.

[3] G. Di Giacomo, L. De Giorgi, I. Ditaranto, G. Leucci, I. Miccoli, G. Scardozzi, The contribution of geophysical prospecting to the reconstruction of the ancient topography of the Messapian necropoleis in Lecce, in Proceedings of the 1 st IMEKO International Conference, 2015, pp. 527-533).

[4] L. Giardino, Per una definizione delle trasformazioni urbanistiche di un centro antico attraverso lo studio delle necropoli: il caso di Lupiae, in Studi di Antichità, 7, pp. 137-203, Galatina, 1994.

[5] L. Giardino, "Lecce-Lupiae", in A. Pranzo (ed.) Salento. Architetture antichi e siti archeologici. Edizioni del Grifo, Lecce, 2008, pp. 53-56.

[6] L. Giardino, N. Lonoce, Le necropoli ad incinerazione di età romana di Lecce e la forma urbana di Lupiae, in M. Lombardo, S. Alessandrì (eds.), Antiquitas. Scritti di storia antica in onore di Salvatore Alessandrì. Congedo, Galatina, 2011, pp. 119-145.

[7] D. Goodman, GPR Slice Version 7.0 Manual, 2013, available online at http://www.gprsurvey.

[8] G. Leucci, 2015. Geofisica Applicata all'archeologia e ai Beni Monumentali. Dario Faccovio Editore Palermo, pp 368.
[9] G. Chávez, A. Tejero, M. A. Alcantara, R. E. Chavez, The 'LArray', a tool to characterize a fracture pattern in an urban zone: Extended Abstracts of the 2011 Near Surface Geophysics meeting, European Section Meeting (Printed in CD), Leicester, UK (2011).

[10] D. Argote-Espino, A. Tejero-Andrade, G. Cifuentes-Nava, L. Iriarte, S. Farías, R. E. Chávez, F. López, 3D electrical prospection in the archaeological site El Pahñu, Hidalgo State, Central Mexico: Journal of Archaeological Science, 40 (2013), pp. 1213-1223.

[11] A. Tejero-Andrade, G. Cifuentes, R. E. Chavez, A. LopezGonzalez, C. Delgado-Solorzano, 2015. L- and Corner-arrays for 3D electrical resistivity tomography: an alternative for urban zones. Near Surf. Geophys. 13, 355e367.

[12] G. Di Giacomo, L. De Giorgi, I. Ditaranto, G. Leucci, I. Miccoli, G. Scardozzi. 2017. Geophysical surveys for the study and reconstruction of the sixteenth-century fortifications of Lecce. Proceedings of $3^{\text {rd }}$ IMEKO International Conference on Metrology for Archaeology and Cultural Heritage, 369-373, ISBN: 978-92-990084-0-9. 